\title{
ENSINO DE FUNÇÃO AFIM ATRAVÉS DA RESOLUÇÃO DE PROBLEMAS: UMA INTERVENÇÃO NO ENSINO MÉDIO
}

\section{TEACHING AFFINE FUNCTION THROUGH PROBLEM SOLVING: AN INTERVENTION PROPOSAL IN HIGH SCHOOL}

\author{
Adalgisa Loureiro de Mello' \\ Janecler Aparecida Amorin Colombo²
}

\begin{abstract}
RESUMO: O presente artigo é recorte de uma pesquisa, concluída em 2018 e vinculada ao Mestrado Profissional em Rede Nacional (PROFMAT), ofertado pela Universidade Tecnológica Federal do Paraná (UTFPR) - campus Pato Branco, tendo objeto da abordagem uma proposta de ensino de Função Afim com base na Metodologia de Ensino-Aprendizagem-Avalição através da Resolução de Problemas. Para tanto, fezse uma adaptação da proposta de Onuchic e Allevato (2011), compactando as dez etapas das autoras em quatro momentos. Para o desenvolvimento da proposta, elaborou-se um "Problema Gerador" baseado em situações relacionadas ao curso Técnico em Serviços Jurídicos do IFPR - Campus Palmas, no qual a intervenção pedagógica foi realizada, especificamente em uma turma de 1 ano. A pesquisa teve cunho qualitativo e buscou verificar a percepção dos alunos frente ao encaminhamento diferenciado das aulas em relação ao conteúdo trabalhado. Os dados coletados foram analisados conforme a triangulação de métodos (GOMES, 2010). Os resultados revelaram que os alunos aderiram ao trabalho de forma positiva; quanto à aprendizagem, foi tida como satisfatória, considerando uma única exposição da metodologia. Além disso, constatou-se uma mudança de postura da professora pesquisadora e da grande maioria dos alunos diante da proposta aplicada, com quesitos fundamentais para instigar a autonomia e a motivação do educando. Ademais, a proposta desenvolvida é apresentada como um protótipo que pode ser aproveitada e utilizada por outros docentes que demonstrarem interesse em conhecer e aplicar a Metodologia de Ensino-AprendizagemAvaliação através da Resolução de Problemas.
\end{abstract}

PALAVRAS-CHAVE: Metodologia de Ensino-Aprendizagem e Avaliação. Resolução de Problemas. Ensino de Função Afim.

ABSTRACT: The present paper is an extract of research completed in 2018 linked to Mestrado Profissional em Rede Nacional em Matemática (PROFMAT), offered by Universidade Tecnológica Federal do Paraná (UTFPR)- campus Pato Branco, whose object was a teaching proposal of Affine Function based on Methodology of teaching-learning-assessment through Problem Solving. For this, an adaptation of the proposal by Onuchic e Allevato (2011) was made, compressing the ten steps by the authors in four moments. To develop the proposal, a "Generation Problem" was elaborated based on situations related to the Technical Course in Legal Services at the Instituto Federal do Paraná (IFPR) - campus Palmas, in which the pedagogical intervention was carried, specifically in a first-year class. The research was qualitative and sought to verify the students' perceptions of the differentiated routing of the classes. The data collected was analyzed by triangulation of methods (Gomes, 2010). The results revealed that the students adhered to the work positively. The learning was considered satisfactory. In addition, a change in the attitude of the researcher teacher and the vast majority of students towards the applied proposal was found, with fundamental requirements to instigate the student's autonomy and motivation. Furthermore, the proposal developed is presented as a prototype that can be used by other teachers who show interest in learning about and applying the ProblemSolving Teaching-Learning-Assessment Methodology.

\footnotetext{
1 Instituto Federal do Paraná. E-mail: adalgisa.mello@ifpr.edu.br

iD https://orcid.org/0000-0003-3876-202X

2 Universidade Tecnológica Federal do Paraná. E-mail: janecler@utfpr.edu.br

(D) https://orcid.org/0000-0002-7729-9501

- Informações completas da obra no final do artigo
} 


\section{ENSIN@UFMS 2021}

ISSN 2525-7056

KEYWORDS: Teaching-Learning-Assessment Methodology. Problem-Solving. Teaching of Affine Function.

\section{Introdução}

Este artigo apresenta um recorte de uma pesquisa de mestrado cujo objeto de estudo foi o desenvolvimento de uma proposta de ensino com tema "Função Afim", a partir da perspectiva teórico-metodológica da Resolução de Problemas (MELLO, 2018). O objetivo da pesquisa era inovar por meio da implementação de uma prática pedagógica viável para as aulas de Matemática, utilizando para isso, especificamente, a Metodologia de EnsinoAprendizagem-Avaliação através da Resolução de Problemas, proposta por Onuchic e Allevato (2011). Partindo desses pressupostos, desenvolveu-se um trabalho de construção e aplicação de uma proposta de aulas baseadas nessa metodologia.

O plano de trabalho desenvolvido foi aplicado em uma turma de 1ª série do Ensino Médio, com alunos do curso Técnico em Assuntos Jurídicos do IFPR Campus-Palmas. Cabe ressaltar que a avaliação nessa instituição é conceitual, o que provocou o interesse na adequação da Metodologia de Ensino-Aprendizagem-Avaliação através da Resolução de Problemas, a esse tipo de processo avaliativo. Desse modo, a avaliação, tema digno de reflexão e que compõe o currículo de Matemática na Educação Básica por impactar diretamente as ações da sala de aula, trouxe grandes contribuições ao desenvolvimento dessa pesquisa, que se propôs a experienciar a inovação metodológica. Porém, devido à relevância do assunto, este será abordado de forma mais específica em um próximo trabalho.

Este artigo foi estruturado em quatro seções, além desta introdução. $\mathrm{Na}$ primeira, apresentamos a abordagem da Metodologia de Ensino-Aprendizagem-Avaliação através da Resolução de Problemas proposta por Onuchic e Allevato (2011). Em seguida, tratamos sobre aspectos operacionais dessa abordagem metodológica e na terceira seção trazemos a proposta desenvolvida para o ensino de Função Afim, apresentando as percepções dos alunos quanto às aulas desenvolvidas a partir desta estratégia metodológica. E, por fim, são apresentadas as considerações finais. 


\section{A Resolução de Problemas como uma Estratégia Metodológica de Ensino- Aprendizagem e Avaliação de Matemática na Perspectiva de Onuchic e Allevato}

Em nível mundial, no que se refere ao ensino de Matemática, nos anos 80 a Resolução de Problemas já se encontrava em alta como Metodologia de ensino. Entretanto, no Brasil foi nesse momento que se deu o início das discussões sobre a temática, sendo que o seu ápice ocorreu apenas em 1997, com a divulgação dos Parâmetros Curriculares Nacionais (PCNs), documento que serviu como subsídio para apoiar o projeto curricular da escola e que encara a utilização da resolução de problemas como estratégia de ensino. Com a publicação da Base Nacional Comum Curricular (BNCC), no final de 2017, mais especificamente em 2018, quando é finalizada a etapa do documento que se refere ao Ensino Médio, observa-se que o foco foi a construção de uma visão integrada da Matemática, aplicada à realidade. É possível, verificamos em vários pontos do documento a presença de termos como "resolução de problema", "argumentação consistente", "mecanismos criativos para encontrar soluções" entre outras expressões que revelam, mesmo de forma implícita e bem sutil, referências sobre a metodologia de ensino através da resolução de problemas. Vale aqui considerar que em termos de avanços da pesquisa em educação matemática, tem-se um retrocesso, uma vez que os PCNs, traziam maior ênfase as diferentes possibilidades metodológicas para o ensino de matemática.

Em se tratando de iniciativas brasileiras, a partir de 1992 foi criado no Brasil o Grupo de Trabalho e Estudo em Resolução de Problemas - GTERP, na Universidade Estadual Paulista (UNESP), em Rio Claro, sendo o trabalho dos pesquisadores coordenado pela Profa. Dra. Lourdes de la Rosa Onuchic. Ainda hoje na coordenação, um de seus principais objetivos é o de manter o grupo atualizado quanto às concepções em Educação Matemática, que, atualmente, se apoia no Ensino-Aprendizagem-Avaliação de Matemática através da Resolução de Problemas, como metodologia de ensino (GTERP, 2017). As pesquisas incessantes na área de Educação Matemática no Brasil e no mundo se devem a crescente necessidade de adequar à matemática aprendida nas escolas às necessidades das diversas áreas de atuação do homem no mundo contemporâneo, já que é uma área do conhecimento indispensável ao desenvolvimento de diversas áreas das ciências.

No que se refere ao ensino de Matemática através da Resolução de Problemas existe uma preocupação com a Matemática e com a Resolução se Problemas no sentido de ambas desenvolverem-se de maneira simultânea ao longo do processo. Visto que as 


\section{ENSIN@UFMS 2021}

ISSN 2525-7056

demandas altamente tecnológicas, a economia crescente e competitiva requerem mudanças na forma de aprender Matemática, necessita-se que os educandos desenvolvam habilidades de autonomia, criticidade, sejam "construtores" do seu próprio conhecimento e ainda consigam trabalhar de forma coletiva, sobrevivendo assim, as rápidas e crescentes modificações a que serão expostos, nas mais diversas experiências de trabalho.

Objetivando o desenvolvimento dessas aptidões durante a formação escolar, o grupo GTERP aposta na "Metodologia de Ensino - Aprendizagem-Avaliação de Matemática através da Resolução de Problemas", pois conforme Onuchic (2014), nesta metodologia, o ensino e aprendizagem acontecem de forma concomitante durante o processo de construção do conhecimento. Justificando-se assim, o uso pelo GTERP da expressão "ensino-aprendizagem", relacionando ambas de forma que ocorram integradas nas situações de sala de aula.

Cabe ainda ressaltar que a metodologia em questão integra um conceito atual de avaliação, sendo esta formativa e continuada, construída durante a resolução do problema, incorrendo-se mais ao processo e menos aos resultados finais obtidos, possibilitando também a reorientação da prática docente. Deste modo, a palavra composta ensinoaprendizagem-avaliação expressa à simultaneidade desses três pilares educacionais durante o processo de construção do conhecimento pelo aluno, mediado pelo professor.

A compreensão e o desenvolvimento da metodologia se dão a partir da clareza advinda do conceito do que é um problema. Para o GTERP problema "é tudo aquilo que não se sabe fazer, mas que se está interessado em fazer" (ONUCHIC; ALLEVATO, 2011, p. 81), e é essa perspectiva vislumbrada por este trabalho.

Quanto à resolução do problema, não devem ser prescritos métodos, afinal o problema dependerá diretamente da pessoa que irá resolvê-lo; se esta já conhece ou já sabe os métodos que deverá utilizar para resolver ou ainda, se não apresenta interesse em resolvê-lo, situação que faz com que o problema não seja considerado como tal. Dessa forma, o que é problema para uma pessoa pode não ser problema para outra. Ainda, se um problema é resolvido várias vezes ou se anteriormente algum problema similar já foi resolvido, o caso deixa de se configurar um problema.

Assim, aprendizagem e a construção do conhecimento são dadas a partir da resolução do problema, por meio de um trabalho colaborativo entre professor e alunos: 
Na Metodologia de Ensino-Aprendizagem-Avaliação de Matemática através da Resolução de Problemas o problema é o ponto de partida e, na sala de aula através da resolução de problemas, os alunos devem fazer conexões entre diferentes ramos da Matemática, gerando novos conceitos e novos conteúdos (ONUCHIC; ALLEVATO, 2011, p. 81).

Para se colocar em prática a Metodologia de Ensino-Aprendizagem-Avaliação de Matemática através da Resolução de Problemas não existe um "modelo" estanque, porém de acordo com a proposta de Onuchic e Allevato et al. (2014) pode ser trabalhada com uma sugestão de dez etapas:

(1). Preparação do problema (seleção ou elaboração de um problema que possibilite a construção de um novo conceito- problema gerador);

(2). Leitura individual;

(3). Leitura em conjunto (formar grupos de trabalho);

(4). Resolução do problema (em grupo);

(5). Observar e incentivar (professor com papel de mediador, questionador e observador do trabalho coletivo, bem como incentivador da utilização de conhecimentos anteriores e de técnicas matemáticas para a resolução do problema gerador. $\mathrm{O}$ auxílio deve ser dado apenas na resolução de problemas secundários que possam aparecer no decorrer da resolução do problema e impeçam a continuação do trabalho);

(6). Registro das resoluções na lousa (representantes do grupo, apresentam a resolução obtida para o problema na lousa);

(7). Plenária (todos os alunos têm a possibilidade de discutir as diferentes resoluções apresentados na lousa);

(8). Busca do consenso (após sanadas as dúvidas e analisadas as resoluções, o professor tenta juntamente coma a turma chegar a um consenso quanto a resultado mais adequado ao problema);

(9). Formalização do conteúdo (apresentação formal do conteúdo na lousa (conceito, linguagem matemática, princípios etc.) pelo professor);

(10). Proposição e resolução de novos problemas (propor novos problemas que se relacionem ao problema gerador, bem como possibilitem a compreensão do conteúdo matemático introduzido naquela aula, possibilitando a consolidação das aprendizagens). 
A sequência das etapas acima tem o objetivo de orientar o trabalho do professor que pretende desenvolver suas aulas a partir desta abordagem metodológica. Uma das etapas principais e que demanda empenho e uma atenção mais detalhada é a "Preparação do problema", que consiste na busca ou elaboração do problema gerador ideal a ser aplicado. Isso porque o problema gerador é a base de todo o processo que se desenvolverá, e os livros didáticos muitas vezes, não trazem problemas com as características necessárias para isso. Corá (2019) discute sobre isso em sua pesquisa de mestrado, concluindo que nos livros didáticos que ela analisou, praticamente inexistem problemas que podem ser considerados como problemas geradores, sendo este um dos motivos que pode explicar a baixa adesão de professores a esta metodologia.

Reitere-se que, nessa metodologia, os problemas são propostos aos alunos antes de Ihes ter sido apresentado formalmente o conteúdo matemático necessário ou mais apropriado à sua resolução que, de acordo com o programa da disciplina para a série atendida, é pretendido pelo professor. Dessa forma, o ensino-aprendizagem de um tópico matemático começa com um problema que expressa aspectos-chave desse tópico e técnicas matemáticas devem ser desenvolvidas na busca de respostas razoáveis ao problema dado. A avaliação do crescimento dos alunos é feita, continuamente, durante a resolução do problema (ONUCHIC; ALLEVATO, 2009, p. 98).

O problema gerador é, portanto, essencial para o desenvolvimento da Metodologia de Ensino-Aprendizagem-Avaliação de Matemática através da Resolução de Problemas, uma vez que dispensa a necessidade de conhecimento prévio do conteúdo matemático envolvido, não exigindo método especifico para a resolução. Somente após a apresentação da resolução dos alunos (etapas 6 a 8) é que o professor formalizará o conteúdo propriamente dito, conteúdo esse, discutido e pesquisado durante o desenvolvimento do problema até a chegada da solução.

Nesse sentido é natural que professor e alunos apresentem uma postura bem diferente daquela observada em uma aula expositiva tradicional.

\section{O Papel do Professor no Desenvolvimento da Metodologia de Ensino-Aprendizagem-} Avaliação de Matemática através da Resolução de Problemas

O docente que pretender aplicar a Metodologia de Ensino-Aprendizagem-Avaliação de Matemática através da Resolução de Problemas deve ter a coragem de inovar, proporcionando ao seu aluno no mínimo, uma proposta diferente da habitual. De certa 
forma, invertendo o que tradicionalmente se faz em sala, que de modo geral é apresentar as definições e depois exercitar e propor problemas.

Ou seja, o docente precisa compreender que haverá mudanças significativas em seu "papel", pois deixará de ser o protagonista em suas aulas. Entretanto, a sua importância não diminui, pois é ele o organizador e mediador no desenvolvimento de todas as atividades, tendo como incumbência: i) esclarecer aos alunos a proposta metodológica e a forma de avaliação; ii) propor o problema gerador (considerando os conhecimentos prévios dos alunos e o conteúdo que pretende desenvolver a partir deste problema); iii) organizar a turma em grupos de trabalho e analisar cada um em sua individualidade; iv) orientar os grupos e perceber as principais dificuldades; v) propiciar que a discussão ocorra entre o maior número de componentes do grupo estimulando assim o trabalho colaborativo; vi) avaliar todo o processo de resolução desempenhado pelo aluno; vii) utilizar os erros como fonte de informação para mediar o processo e subsidiar a auto avaliação do aluno; viii) formalizar o conteúdo, utilizando a linguagem matemática e aproveitando as diferentes resoluções e técnicas operatórias propostas pelos alunos.

Da mesma forma é igualmente importante uma mudança significativa na postura do estudante. Para garantir a eficácia da proposta é necessário que os estudantes compreendam e assumam suas responsabilidades frente ao processo, e que, portanto, sejam participativos (ONUCHIC; ALLEVATO, 2011).

Refletindo sobre o papel do professor ao assumir essa metodologia e pensando em tornar a aplicação viável, diante das situações enfrentadas pelos docentes em sala de aula, tais como: disciplina com carga horária reduzida, número elevado de alunos por turma, quantidade elevada de conteúdo a ser desenvolvida ao longo do ano, entre outras situações, propusemos uma síntese das etapas sugeridas por Onuchic e Allevato (2011, 2014) compactadas em quatro momentos, conforme disposição abaixo:

$1^{\circ}$ Momento - Leitura e Interpretação: Divisão da turma em grupos, seguida da entrega do problema gerador individualmente a cada integrante do grupo. Disponibilização de tempo para que seja feita leitura do problema de forma individual e em grupo. Auxílio do professor nos grupos para interpretação do problema, caso se faça necessário; Resolução do Problema- os alunos a partir da interpretação e entendimento do problema buscam em grupo resolvê-lo.

$2^{\circ}$ Momento - Demonstração da Resolução do Problema em Grupo - Cada grupo utiliza-se de um ou dois representantes para registrar na lousa a resolução e explicar quais as estratégias utilizadas, independentemente de estar certa ou errada. Em seguida, todos os alunos são convidados a discutir as resoluções expostas na lousa, e o professor age como incentivador e mediador das colocações. Esclarecidas as 
dúvidas, o professor procura chegar com todos a um consenso sobre resultado correto.

$3^{\circ}$ Momento - Apresentação Formal do Conteúdo - O professor faz a apresentação formal do conteúdo, organizado e estruturado na linguagem matemática, esse é o momento em que os alunos têm o contato como conteúdo propriamente dito.

$4^{\circ}$ Momento - Proposição de Novos Problemas - Tais problemas tem objetivo de aprofundar e aumentar a compreensão do tal conteúdo matemático, configurando uma forma de construir conhecimento através da resolução de problema (MELLO, 2018, p. 38).

Esta reorganização pode ser facilmente observada no Quadro 1:

Quadro 1. As 10 etapas da Metodologia de Ensino-Aprendizagem-Avaliação através da Resolução de Problemas de Onuchic e Allevatto (2014) em 4 momentos

\begin{tabular}{|c|c|}
\hline (1) Preparação do problema & \multirow{5}{*}{$\begin{array}{l}1^{\circ} \text { Momento } \\
\text { Leitura e interpretação }\end{array}$} \\
\hline (2) Leitura individual & \\
\hline (3) Leitura em conjunto & \\
\hline (4) Resolução do problema & \\
\hline (5) Observar e incentivar & \\
\hline (6) Registro das soluções na lousa & \multirow{3}{*}{$\begin{array}{l}\qquad 2^{\circ} \text { Momento } \\
\text { Demonstração da resolução do problema gerador }\end{array}$} \\
\hline (7) Plenária & \\
\hline (8) Busca do consenso & \\
\hline (9) Formalização do Conteúdo & $\begin{array}{c}3^{\circ} \text { Momento } \\
\text { Apresentação formal do conteúdo }\end{array}$ \\
\hline (10) Proposição e resolução de novos problemas & $\begin{array}{l}4^{\circ} \text { Momento } \\
\text { Proposição de novos problemas }\end{array}$ \\
\hline
\end{tabular}

Fonte: Mello (2018).

Durante o desenvolvimento dos quatro momentos da metodologia transcorre também o processo avaliativo, que em nossa proposta é embasado em uma ficha de avaliação e anotações pertinentes realizadas em diário de campo. Este instrumento foi elaborado em Mello (2018) e será objeto de um outro artigo específico sobre processos avaliativos.

Na próxima seção apresentamos um exemplo de intervenção no Ensino Médio, baseado nestes quatro momentos para aplicação da Metodologia de EnsinoAprendizagem-Avaliação de Matemática através da Resolução de Problemas.

\section{Resolução de Problemas como Metodologia para o Ensino-Aprendizagem-Avaliação de Função Afim}

A aplicação da proposta foi realizada em uma turma do $1^{\circ}$ Ano de Ensino Médio, do curso Técnico em Serviços Jurídicos, do IFPR Campus Palmas no ano de 2018. Esta turma era composta por 43 alunos, um número expressivo, causando certa preocupação diante de uma metodologia não utilizada até então. 
O desenvolvimento da proposta didática se deu a partir do tema Função Afim (definição, construção do gráfico, crescimento e decrescimento, coeficiente angular e linear, zeros da função), logo o problema gerador proposto precisaria englobar ou pelo menos propiciar a discussão sobre o tema e os itens elencados.

O problema gerador foi elaborado considerando as seguintes hipóteses:

i. Alunos possuem conhecimentos básicos de Função Afim e construção de gráficos, adquiridos no 9 a ano do Ensino Fundamental;

ii. Alunos possuem conhecimento de funções, conforme descrito em plano de ensino da disciplina de Matemática do $1^{\circ}$ ano;

iii. A prática despertaria a vontade de aprender.

Incialmente a ideia era utilizar um problema pronto, entretanto os problemas encontrados não atendiam as especificidades desejadas. Buscando a melhor aplicação da metodologia, partiu-se para a elaboração do problema gerador. Foi escolhido um tema que fizesse parte do contexto dos alunos, não para facilitar a resolução, mas para visualizarem a aplicabilidade do conteúdo que seria posteriormente desenvolvido.

A ideia foi acertada, e o problema foi tomando "corpo", de maneira que a partir do seu desenvolvimento, foi possível abordar grande parte do conteúdo de Função Afim. 
Figura 1: Problema Gerador

Problema Gerador

Em nossa cidade há três lojas credenciadas as operadoras de celular: Loja da TCHAU, Loja da ESCURO e Loja da TUM.

Um estudante do IFPR visando diminuir suas despesas com telefone móvel e manter suas necessidades atendidas fez uma pesquisa referente a planos pós-pago, conforme abaixo:

\begin{tabular}{|c|c|c|c|c|}
\hline \multicolumn{5}{|c|}{ RA ESC } \\
\hline Plano & \multicolumn{2}{|c|}{ Valor Mensal } & \multicolumn{2}{|c|}{ Valor por min Extra } \\
\hline $50 \mathrm{~min}$ & $\mathrm{RS}$ & 42,99 & $\mathrm{RS}$ & 0,50 \\
\hline $100 \mathrm{~min}$ & $\mathrm{RS}$ & 68,99 & $\mathrm{R} \$$ & 0,50 \\
\hline $150 \mathrm{~min}$ & R\$ & 109,99 & $\mathrm{RS}$ & 0,50 \\
\hline \multicolumn{5}{|c|}{ OPERADORA TUM } \\
\hline Plano & \multicolumn{2}{|c|}{ Valor Mensal } & \multicolumn{2}{|c|}{ Valor por min Extra R\$ } \\
\hline $50 \mathrm{~min}$ & $\mathrm{R} \$$ & 40,00 & RS & 0,75 \\
\hline $100 \mathrm{~min}$ & $\mathrm{R} \$$ & 66,00 & $\mathrm{R} \$$ & 0,75 \\
\hline $150 \mathrm{~min}$ & $R \$$ & 105,00 & $\mathrm{R} \$$ & 0,75 \\
\hline \multicolumn{5}{|c|}{ OPERADORA TCHAU } \\
\hline Plano & \multicolumn{2}{|c|}{ Valor Mensal } & \multicolumn{2}{|c|}{ Valor por min Extra R\$ } \\
\hline $50 \mathrm{~min}$ & $\mathrm{R} \$$ & 39,99 & $\mathrm{RS}$ & 0,89 \\
\hline $100 \mathrm{~min}$ & $\mathrm{R} \$$ & 64,99 & $\mathrm{RS}$ & 0,89 \\
\hline $150 \mathrm{~min}$ & $\mathrm{RS}$ & 100,99 & RS & 0,89 \\
\hline
\end{tabular}

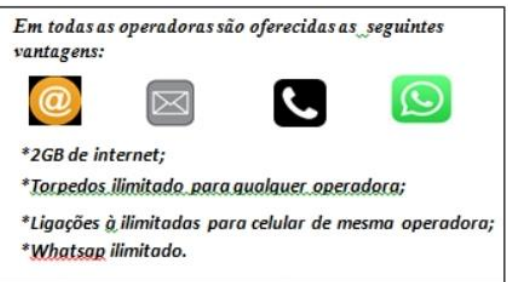

Analisando as informações obtidas pelo estudante, responda as questões abaixo:

a) Explique como é feito o cálculo do valor a ser pago de uma fatura de telefonia celular em planos pós-pagos, conforme disposto.

b) Se o estudante utilizasse em média 90 minutos por mês, em que operadora e qual o plano seria mais vantajoso a ele? Justifique sua resposta através de cálculos

c) Acredita-se que se este aluno fosse do Ensino Médio seu perfil se enquadraria no plano de 50min. Qual a operadora deveria ser escolhida levando em conta fator economia, caso ultrapassasse o tempo da franquia em $13 \mathrm{~min}$ ? Qual seria o valor pago no mês considerado? Qual a maior economia obtida relativa ao mesmo plano em outra operadora?

d) Quando o plano de 150 minutos for excedido, em quanto tempo as faturas da operadora TUM e TCHAU terão praticamente o mesmo valor cobrado no mês? Justifique

e) Qual é o modelo matemático que relaciona o valor a ser pago e os minutos extras usados, em qualquer uma das situações dispostas nos planos pós-pagos de qualquer operadora?

Fonte: Mello (2018, p. 108-110) 
Figura 2: Continuação Problema Gerador

f) Escolhendo a operadora TUM e um plano de $50 \mathrm{~min}$, construa um gráfico onde seja possível visualizar o valor da conta em reais ao final do mês, considerando as seguintes situações:

I) O usuário não utilizou o telefone,

II) O usuário utilizou $20 \mathrm{~min}$ da franquia,

III) O usuário utilizou $33 \mathrm{~min}$ da franquia,

IV) O usuário utilizou $50 \mathrm{~min}$,

V) O usuário utilizou 60 min da franquia,

VI) O usuário utilizou 70 min da franquia,

VII) $\mathrm{O}$ usuário utilizou $80 \mathrm{~min}$ da franquia.

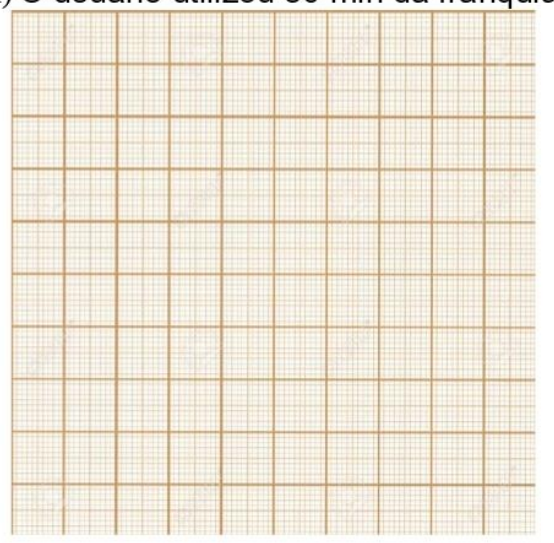

g) Com relação ao gráfico construído no item (f) responda:

g1) Qual é o de tempo de utilização em minutos em que não há variação do valor da conta?

$\mathrm{g}_{2}$ ) O que acontece com o valor da conta, quando o estudante passa a consumir mais do que a franquia estabelecida em min?

g3) É possível traçar uma linha por esses pontos obtidos no gráfico? Justifique sua resposta matematicamente

g4) Se é possível ligar esses pontos através de uma linha, é necessário que se faça alguma adequação no enunciado do problema? Justifique

g5) Conforme o gráfico, como pode variar o valor da conta a ser paga ao final de cada mês?

Observações quanto a resolução:

Fonte: Mello (2018, p. 108-110).

A elaboração do problema gerador foi sem dúvida a maior dificuldade encontrada para a aplicação da metodologia. O que não foi possível abordar no problema gerador foi 
desenvolvido a partir de problemas auxiliares propostos pelo professor no $3^{\circ}$ momento da proposta.

Posteriormente, foi possível observar que a elaboração assertiva desse problema foi um dos pontos positivos da proposta, uma vez que possibilitou o bom desenvolvimento da metodologia a partir de um problema que pode servir como um protótipo inicial para possíveis interessados na Metodologia de Ensino-Aprendizagem-Avaliação através da Resolução de Problemas.

A proposta foi planejada para ser desenvolvida em 6 horas/aula de 45 min cada uma, conforme quadro abaixo:

Quadro 2. Planejamento da proposta de aplicação, distribuição tempo para cada momento

\begin{tabular}{|c|c|c|c|}
\hline \multicolumn{4}{|c|}{1 semana +2 semana $=6$ horas/aula } \\
\hline $1^{\circ}$ Momento & $2^{\circ}$ Momento & $3^{\circ}$ Momento & $4^{\circ}$ Momento \\
\hline 2 aulas & 1,5 aula & 1 aula & 1,5 aula \\
\hline
\end{tabular}

Fonte: Mello (2018, p. 61)

Antes mesmo da intervenção a pesquisadora organizou os grupos de trabalho fazendo uso da lista de chamada para otimizar o tempo da aplicação da proposta. Dividiu a turma em oito grupos (três grupos com seis alunos e cinco grupos com cinco alunos) usando a sistemática de ordem, que também possibilitou a mesclar os alunos de diferentes níveis de aprendizagem.

No $1^{\circ}$ Momento: Leitura e Interpretação - Acompanhando o desenvolvimento dos grupos, percebeu-se que todos conseguiram realizar a proposta sem dificuldade, exceto um dos grupos, que acabou recebendo então, maior apoio para que pudessem superar as dificuldades apresentadas.

O fator tempo foi o grande limitante a todos, houve a necessidade de ampliação para o desenvolvimento das atividades propostas no $1^{\circ}$ momento, sendo este expandido dentro das possibilidades consideradas pela professora pesquisadora.

A maioria dos alunos demonstrou interesse sobre o problema gerador, lendo com muita atenção, tentando compreender e contribuir com seu grupo durante a resolução. Tal fato "saltou aos olhos" da professora pesquisadora, pois a postura dos alunos diante da proposta foi muito boa, uma vez que eles assumiram o protagonismo na resolução do problema, apesar de, no início da atividade, terem tentado por várias vezes questionar a professora em busca da resposta. Mas, com a ausência de uma devolutiva nesse sentido, 
os integrantes da turma se deram conta de que o trabalho "árduo" de entender e formalizar as respostas caberia a eles, e assim fizeram-no. A leitura, interpretação e resolução do problema fazem do $1^{\circ}$ Momento etapa fundamental, que atrelada ao exposto, necessitou de uma ampliação no tempo previamente estabelecido no planejamento para sua efetiva conclusão.

Na realização do $2^{\circ}$ Momento: Demonstração da Resolução do Problema em Grupo - a professora organizou os "grupos" de carteiras em forma de meia lua, antes da chegada dos alunos em sala (sempre tentando otimizar o tempo). Tal organização espacial possibilitou que todos os alunos estivessem voltados para o local onde seriam expostas as resoluções, sendo também uma maneira pensada de evitar conversas, preocupação da professora pesquisadora até aquele momento, e reflexo talvez de sua formação mais tradicional, que entende a atividade em grupo como uma preocupação, pois as interferências podem atrapalhar o processo de aprendizagem e afastar a turma do objetivo estabelecido para aula. $O$ relato desse receio revelou também que a postura da professora pesquisadora foi mudando de forma bem gradativa.

Chegada a hora de expor aos colegas e à professora a resolução realizada e a resposta encontrada para a resolução do problema apresentado, pode-se constatar que a organização do procedimento adotado pelos grupos, bem como a escrita matemática foram satisfatórias.

Nesta forma de exposição da resolução do problema por parte dos alunos, a professora pesquisadora não focou o olhar nos erros, uma vez que os utilizou para mostrar alguns apontamentos importantes do processo: onde a leitura deveria ter sido mais efetiva; que todo desenvolvimento estaria correto, porém por falha de cálculo a resposta final ficou errada; ou ainda que todo desenvolvimento estava correto, porém a interpretação foi equivocada. Enfim, todo desenvolvimento estabelecido pelos alunos foi considerado para reflexão e aprendizado, o que de acordo com Pavanello e Nogueira (2006, p. 36) é altamente produtivo:

"Se os erros forem encarados com naturalidade e racionalmente tratados, terão assim importância pedagógica, deixando de apenas serem assinalados e passando a compor o processo avaliativo, sendo objetos de uma análise específica do professor com o estudante".

No planejamento do $2^{\circ}$ Momento cada grupo deveria escrever a resolução do problema gerador na lousa e, em seguida, explicar aos colegas. Percebendo-se que não 
haveria tempo hábil se mantido esse formato, houve a necessidade de se pensar em algo viável diante da realidade encontrada. A solução foi a organização das respostas dos grupos utilizando recursos tecnológicos. Dessa forma, a resolução feita na folha pelos grupos, foi fotografada e organizada pela professora, utilizando a projeção em slides, para possibilitar aos participantes de cada grupo, explicação, argumentação e discussão da sua resolução, e ainda a garantia da agilidade no processo.

A participação dos alunos foi bem satisfatória nesse momento, visto que explanavam a interpretação do grupo, diante de cada pergunta do problema, demonstrando o raciocínio usado na resposta apresentada naquele momento. Quando questionados, sendo levados a "defender" a sua resposta, conseguiam argumentar considerando o enunciado e o que os levou a formalizar a resposta da forma construída. Sempre que necessário foram feitas intervenções pela professora pesquisadora.

No $3^{\circ}$ Momento - Apresentação formal do conteúdo - o conteúdo de Função Afim foi explicado pela professora pesquisadora na lousa através de aula expositiva dialogada. Para o professor é um momento confortável, porém a metodologia exige que o problema gerador seja revisitado o tempo todo, sendo retomado para a explicação do conteúdo.

$\mathrm{Na}$ Metodologia de Ensino-Aprendizagem-Avaliação de Matemática através da Resolução de Problemas o problema é o ponto de partida e, na sala de aula através da resolução de problemas, os alunos devem fazer conexões entre diferentes ramos da Matemática, gerando novos conceitos e novos conteúdos (ONUCHIC; ALLEVATO, 2011, p. 81).

A elaboração do problema gerador possibilitou desenvolver a maior parte do conteúdo de Função Afim, facilitando o desenvolvimento da aula expositiva a partir de sua resolução.

Reitera-se que nesta metodologia, os problemas são propostos aos alunos antes de lhes ter sido apresentado, formalmente o conteúdo matemático necessário ou mais apropriado à sua resolução que, de acordo com o programa da disciplina para a série atendida, é pretendido pelo professor (ONUCHIC; ALLEVATO, 2011, p. 85).

A aula expositiva dialogada, desenvolvida no $3^{\circ}$ momento foi mais uma oportunidade para os alunos compreenderem o problema. Para dar conta de explicar todo conteúdo de Função Afim, a professora utilizou problemas auxiliares, uma vez que o problema gerador havia sido totalmente explorado e ainda restavam tópicos do conteúdo a serem abordados.

E, por fim no $4^{\circ}$ Momento: Proposição de Novos Problemas - da intervenção, houve a proposição das atividades complementares (elaboradas em sua maioria pela professora 
pesquisadora). Estas se apresentam como mais uma possibilidade de verificar se houve apropriação do conhecimento, aprendizagem em relação à função afim e se houve o reconhecimento da função em diferentes contextos, estabelecendo uma forma de construir conhecimento através da resolução de problemas.

No planejamento, estava prevista a execução das atividades complementares em sala e de forma individual, entretanto, devido as adequações do tempo no desenvolvimento do $1^{\circ}$ e $2^{\circ}$ momentos, houve a necessidade de se rever o $4^{\circ}$ momento, sendo direcionada a resolução individual das atividades complementares para casa e com prazo de entrega agendando para uma data específica, que contara também com o tramite da correção.

A correção das atividades complementares foi mais um dos instrumentos utilizados para verificação de como se deu a aprendizagem dos alunos.

Finalizada mais essa etapa, percebeu-se que mesmo diante de um planejamento bem elaborado, houve necessidade de adequações no formato da proposta planejada em várias situações, sendo este o papel do professor:

O professor assume o papel de investigador, de esclarecedor, de organizador de experiências significativas da aprendizagem. Seu compromisso é o de agir refletidamente, criando e recriando alternativas pedagógicas adequadas a partir da melhor observação do conhecimento de cada um dos alunos, sem perder a observação do conjunto e promovendo sempre ações interativas (HOFFMANN, 2014, p. 20).

Tal flexibilização se deu principalmente com relação ao tempo necessário para desenvolvimento de cada momento, mas embora tenham acontecido essas adequações da duração de cada momento, não houve extrapolação do tempo total estabelecido (6 horas/aula), evitando o comprometimento da intervenção e o desenvolvimento do planejamento das aulas da turma.

Partindo da análise apresentada, para intervenções futuras sugerimos a adequação do planejamento para a aplicação desse problema gerador da seguinte forma:

Quadro 3. Adequação da distribuição de tempo para cada momento

\begin{tabular}{|c|c|c|c|}
\hline \multicolumn{4}{|c|}{$\mathbf{7}$ horas/aula } \\
\hline $\mathbf{1}^{\circ}$ Momento & $\mathbf{2}^{\circ}$ Momento & $3^{\circ}$ Momento & $4^{\circ}$ Momento \\
\hline 3 aulas & 2 aulas & 1 aula & 1 aula \\
\hline
\end{tabular}

Fonte: A autora (2021).

Permeando esses quatro momentos se deu a avaliação dos alunos, facilitada pela utilização da ficha de avaliação e observações feitas no diário de campo, estabelecendo a 


\section{ENSIN@UFMS 2021}

ISSN 2525-7056

concomitância Ensino-Aprendizagem-Avaliação necessária ao desenvolvimento apropriado da metodologia em questão.

\section{Percepção dos Alunos quanto às Aulas de Função Afim a partir da Metodologia de Ensino- Aprendizagem-Avaliação através da Resolução de Problemas}

A maioria dos alunos (83\%) não haviam tido uma experiência de aula com a Metodologia de Ensino-Aprendizagem-Avaliação através da Resolução de Problemas e, ao serem expostos a essa experiência com o conteúdo de Função Afim, declararam apresentar alguma dificuldade.

Gráfico 1: Tipo de Dificuldade Apresentada pelos Alunos nas aulas com Metodologia de EnsinoAprendizagem-Avaliação através da Resolução de Problemas

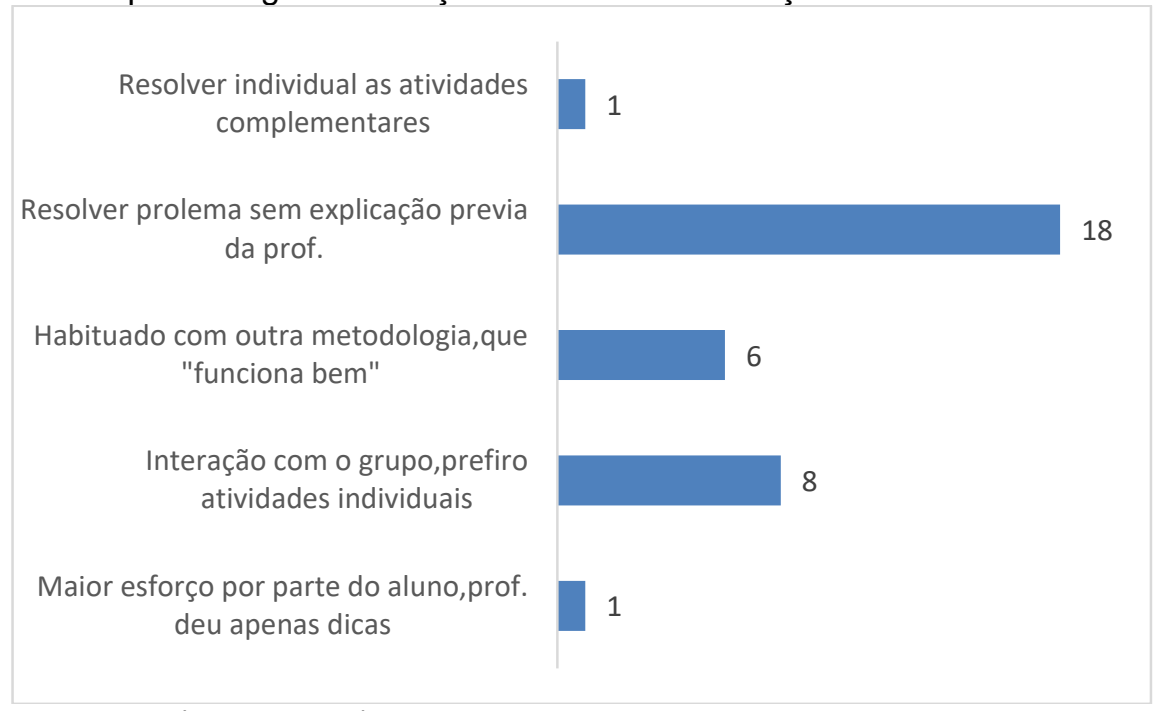

Fonte: Mello (2018, p. 94)

Foi possível perceber muita dificuldade durante a exposição dos envolvidos no processo a algo novo, uma certa resistência à mudança. Isso ficou evidente, pois em vários instantes do desenvolvimento da proposta com a Metodologia de Ensino-AprendizagemAvaliação através da Resolução de Problemas foram destacadas dificuldades que dizem respeito às quebras de rotina, às mudanças no desenvolvimento das aulas:

- Resolução de um problema sem explicação prévia do professor; (1ํ momento);

- Proposta de um trabalho em grupo (em que o individual é mais comum) e a interação entre seus componentes trará um melhor resultado; (1ํㅜㄴํำ momentos);

- Maior empenho e dedicação por parte dos alunos para desenvolver as atividades propostas. ( $1^{\circ}, 2^{\circ}, 3^{\circ}$ e $4^{\circ}$ momentos); 


\section{ENSIN@UFMS 2021}

ISSN 2525-7056

- Alguns alunos por sua vez, deixam claro que estão satisfeitos com o método de ensino, que são as aulas expositivas dialogadas, e preferem evitar situações que possibilitem "sair da zona de conforto".

Conforme Mello (2018) a metodologia proposta requer mais esforço do aluno, interação entre os componentes do grupo, modificação de "velhos" hábitos para que a interpretação e a resolução do problema se concretizem. Isso pode causar estranheza e até uma certa resistência por parte dos alunos habituados ao papel protagonista do professor nas aulas.

Onuchic e Allevato (2011) pontuam que a Metodologia de Ensino- AprendizagemAvaliação através da Resolução de Problemas exige do professor e dos alunos novas posturas e atitudes nos trabalhos em sala de aula. Aos alunos é transferida a maior responsabilidade pela aprendizagem e eles por sua vez devem assumir essa responsabilidade.

Os apontamentos realizados pelos alunos diante das aulas utilizando a metodologia de Ensino-Aprendizagem-Avaliação através da Resolução de Problemas confirma as considerações referenciadas:

AL2: "Esse método é um pouco diferente daquele que a professora usa na sala de aula. Começou um pouco complicado, mas depois fui entendendo".

AL22: "As aulas foram legais e diferentes, no começo foi difícil mais depois logo fui aprendendo".

AL25: "Pra mim foi legal, mais difícil no começo, depois ficou mais fácil".

AL28: "Que foi muito boa, fez com que conseguimos resolver uma avaliação sem sabermos só com o que a gente conhecia e deu super certo".

AL31: "Foi um método de aprendizado muito diferente de todos, por isso achei difícil no começo, mas depois fui no embalo".

Praticamente em todos os comentários, percebe-se que com o desenvolvimento da proposta, a dificuldade inicial vai sendo amenizada, o aluno vai se familiarizando com a metodologia, vão se rompendo as barreiras, o entendimento ganha espaço e o conhecimento vai sendo construído e a nova proposição se torna aceita.

Conforme a metodologia vai se desenvolvendo, o que era inicialmente difícil tornouse fácil, o complexo passa a ser simples e o diferente se torna atrativo. Isso pode ser evidenciado pelos excertos dos alunos: 
AL3: "Foi boa, pois nos desafiou a fazer algo diferente".

AL7: "Nunca tive uma aula deste gênero, mas achei bem efetiva".

AL8: "Seria algo ativo interação maior que a de costume, em vista de como foi, foi muito divertido em razão de ser algo novo”.

AL14: "Criativas, pois é um método novo que quase nunca os professores praticam".

AL19: "Foi uma atividade diferente, mas eu gostei porque aprendemos coisas novas".

A metodologia consegue envolver aluno-colega-professor em todo processo, a resolução do problema deixa de ser responsabilidade exclusiva do professor, passando a ser responsabilidade partilhada, um compromisso de todos os envolvidos. Quando há um esforço coletivo, reconhece-se o do valor do trabalho em equipe.

AL12: "Foi importante e muito interessante, caso fosse sozinho não teria conseguido tudo, mas sendo em grupo foi bom, pois todos se ajudaram".

AL16: "Eu gostei do trabalho em grupo e o modo de resolver os problemas".

As motivações proporcionadas pela Metodologia de Ensino-AprendizagemAvaliação através da Resolução de Problemas resultam em uma mudança significativa de postura do professor e do aluno.

AL26: "Percebi que nos fez pensar mais".

AL21: "Achei a aula muito boa, pois a professora fez com que todos nós participássemos, e dando a explicação sobre cada exercício".

Em todo processo, exige-se mais do aluno, pois este precisa assumir o compromisso de sua aprendizagem, passando a ter maior autonomia sobre suas ações. Já os professores habituados a uma determinada metodologia não conseguirão alterá-la, transformando sua postura com cinco ou seis aulas "diferentes".

Essa mudança é algo muito difícil de ser efetivada, pois quando há o hábito, não é um episódio isolado que promoverá a transformação. O processo é complexo, afinal os envolvidos no processo, professores e alunos, agem como se estivessem mecanicamente programados. Em decorrência disso, há certo estranhamento quando os envolvidos se submetem e são submetidos a uma nova metodologia de Ensino, fazendo com que relutem em alguns casos, até que haja a acomodação e percepção plena de seu funcionamento. No entanto, acredita-se que essa harmonia somente ocorrerá se sua incidência do trabalho for contínua ou até ininterrupta. 
AL18: "Não entendi muita coisa por conta da falta de explicação, porém consegui desenvolver os exercícios muito bem".

Se não houvesse entendido, não conseguiria desenvolver os exercícios propostos. O hábito da explicação, fez com que não percebesse que houve aprendizado.

AL27: "Achei bem bacana, porém ela deveria ter ajudado um pouco mais".

Mesmo que a aula tenha sido interessante, tenha conseguido desenvolver o problema proposto, não está satisfeito. Sua referência de aula ainda está muito centrada na figura do professor, revelando-se inseguro por não o ter a sua disposição, auxiliando-o a todo o momento.

[...] *Resolução de Problemas desenvolve poder matemático nos alunos, capacidade de pensar matematicamente, utilizar diferentes e convenientes estratégias em diferentes problemas, permitindo aumentar a compreensão dos conteúdos e conceitos matemáticos.

*Resolução de problemas desenvolve a crença de que os alunos são capazes de fazer matemática e de que a Matemática faz sentido; a confiança e a autoestima dos estudantes aumentam [...] (ONUCHIC; ALLEVATO, 2011, p. 82).

A Metodologia de Ensino-Aprendizagem-Avaliação através da Resolução de Problemas possibilita preparar o aluno para fugir da dependência em relação ao professor, fazendo com que seja confiante, responsável e autônomo quanto a sua aprendizagem.

A responsabilidade do professor diante da Metodologia de Ensino-AprendizagemAvaliação através da Resolução de Problemas não é menor, pois recai inicialmente sobre a preparação do problema a ser aplicado, na elaboração do plano de aula e não se esgota concluída essa etapa. É de extrema importância no desenrolar de todo o processo, sendo aquele que, atento a tudo, deve estimular a participação, instigar a curiosidade, aguçar o raciocínio, promovendo o desenvolvimento individual de cada um de seus alunos.

Para os alunos é evidente que o entendimento do conteúdo está relacionado com uma aula expositiva dialogada e, quando ocorre uma aula diferente, logo alegam não entender o conteúdo, mesmo que consigam desenvolver outras atividades semelhantes, ou interpretar situações distintas, como conseguimos perceber através da correção das atividades complementares propostas. Convém destacar, que o formato de aula consagrado que tem o foco no processo expositor e não mediador do conhecimento é ainda algo muito latente no ambiente escolar e tido como um hábito ainda muito forte.

AL37: "As aulas foram planejadas muito bem, porém faltou tempo e o modo como foi aplicado os exercícios fez com que muitos não entendessem o conteúdo". 
Como essa foi a primeira intervenção na turma escolhida para o desenvolvimento das atividades tendo por base a Metodologia de Ensino-Aprendizagem-Avaliação através da Resolução de Problemas e pelo fato de que também se configurou em uma das primeiras vezes a que foram submetidos a uma diferente metodologia de ensino nas aulas de matemática considera-se a postura dos alunos bastante positiva, diante de tudo que foi exposto, pois mesmo que ainda estivessem muito presos aos seus hábitos tentaram desenvolver tudo que Ihes foi proposto.

\section{Considerações Finais}

Tomando como base os dados coletados nessa pesquisa, foi possível analisar as percepções dos educandos quanto às aulas e conteúdo diante da aplicação da proposta de aulas de Matemática baseada na Metodologia de Ensino-Aprendizagem-Avaliação através da Resolução de Problemas, sendo verificado que o desenvolvimento do conteúdo de Função Afim foi efetivo a partir da metodologia aplicada na resolução dos problemas propostos (problema gerador e atividades complementares). Apesar de certa resistência quanto à inserção de novas metodologias, a resposta dos alunos à intervenção, de maneira geral, foi positiva enquanto resultado final.

Apesar das expectativas iniciais da professora pesquisadora (que previa dificuldade dos alunos em desenvolver o conteúdo a partir da Metodologia de Ensino AprendizagemAvaliação através da Resolução de Problemas e se apresentava receosa em aplicar uma metodologia diferente da que estava acostumada em uma turma numerosa), o trabalho desenvolveu-se de forma surpreendente, propiciando novos olhares sobre a inclusão de inovação a partir de Metodologias diferenciadas para dentro da sala de aula.

Percebeu-se que o enfrentamento de situações adversas trouxe resultados satisfatórios e animadores, uma vez que o desenvolvimento da proposta se delineou proporcionando uma mudança visível na postura dos alunos e da professora. Os alunos, em sua maioria, se debruçaram sobre o problema gerador para obter respostas e buscaram auxílio necessário com o grupo, conquistando confiança e autonomia jamais imaginadas. Já a professora pesquisadora possibilitou essa mudança, assumindo a postura de não ser a protagonista da aula, mas sim a "condutora" de todo processo, possibilitando a turma alcançar autonomia, criticidade e comprometimento na aprendizagem. 
O resultado positivo não significa que todas as aulas devam ser baseadas em metodologias diferenciadas, já que não há tempo hábil para isso com a atual dinâmica de organização curricular, mas é necessário que metodologias de ensino de matemática diferenciadas tenham espaço nas aulas, mesmo que esporadicamente. Cabe aqui ressaltar que a elaboração do "problema gerador" foi também um grande norteador dessa pesquisa, pois este pode servir como uma opção ou um direcionador dos docentes que desejarem aplicar a metodologia, e que muitas vezes por falta de tempo acabam desistindo antes mesmo de começar.

Espera-se que esta pesquisa encoraje professores a introduzir a Metodologia de Ensino-Aprendizagem-Avaliação através da Resolução de Problemas em suas aulas, uma vez que os resultados obtidos foram surpreendentes. Como a metodologia proposta foi aplicada em apenas um conteúdo específico, não há dados suficientes para saber qual seria a percepção dos alunos quando submetidos com maior frequência a essa metodologia ou ainda, que outras metodologias diferentes poderiam ser utilizadas. Esses questionamentos são importantes e podem ser propulsores de novas ações de pesquisa.

\section{Referências}

CORÁ, J. R. Análise da inserção da resolução de problemas identificada em livros didáticos de matemática do ensino fundamental. 144f. Dissertação (Mestrado em Matemática) - Universidade Tecnológica Federal do Paraná, Pato Branco, 2019.

GOMES, R. et al. Organização, processamento, análise e interpretação de dados o desafio da triangulação. In: MINAYO, M. C. S.; ASSIS, S. G.; SOUZA, E. R. (org.). Avaliação por Triangulação de Métodos: abordagem de programas sociais. Rio de Janeiro: Fiocruz, 2010.

GRUPO DE TRABALHO E ESTUDOS EM RESOLUÇÃO DE PROBLEMAS - GTERP. Disponível em: <http://igce.rc.unesp.br/\#!/departamentos/educacaomatematica/gterp/item-2/>. Acesso em: 09 ago. 2021.

HOFFMANN, J. Avaliar para promover: as setas no caminho. 15. ed. Porto Alegre: Mediação, 2014.

MELLO, A. L. de. Resolução de Problemas e Avaliação Conceitual: Uma Experiência no Ensino de Função Afim. 123f. Dissertação (Mestrado em Matemática) - Universidade Tecnológica Federal do Paraná, Pato Branco, 2018. Disponível em:

$<$ http://repositorio.utfpr.edu.br/jspui/handle/1/3343>. 
ONUCHIC, L. R. et. al. Resolução de Problemas: teoria e prática. Jundiaí: Paco Editorial, 2014.

ONUCHIC, L. R.; ALLEVATO, N. S. G. Pesquisa em Resolução de problemas: caminhos avanços e novas perspectivas, p. 73-98. In: Boletim de Educação Matemática (BOLEMA), v. 25, n. 41, dez., 2011. Universidade Estadual Paulista - Campus de Rio Claro. Ed. Comemorativa 25 anos.

PAVANELLO, R. M.; NOGUEIRA, C. M. I. Avaliação em Matemática: algumas considerações. Estudos em Avaliação Educacional, Revista Quadrimestral, Fundação Carlos Chagas, v. 17, n. 33, p. 29-41, jan./abr., 2006.

\section{NOTAS}

\section{IDENTIFICAÇÂO DO TEXTO}

O presente texto é um recorte de Resolução de problemas e avaliação conceitual: uma experiência no ensino de função afim, dissertação de Mestrado Profissional em Matemática em Rede Nacional (PROFMAT) apresentado na Universidade Tecnológica Federal do Paraná (UTFPR), Campus Pato Branco, em 23 de maio de 2018, elaborada sob orientação da Professora Dra. Janecler Aparecida Amorin Colombo.

\section{IDENTIFICAÇÃO DE AUTORIA}

Adalgisa Loureiro de Mello. Mestre em Matemática pela Universidade Tecnológica Federal do Paraná (UTFPR), Campus Pato Branco. Professora do Instituto Federal do Paraná (IFPR), Campus Palmas, Palmas, PR, Brasil.

E-mail: adalgisa.mello@ifpr.edu.br

(iD) https://orcid.org/0000-0003-3876-202X

Janecler Aparecida Amorin Colombo. Doutora em Educação Científica e Tecnológica pela Universidade Federal de Santa Catarina. Professor Associado Nível 3. Universidade Tecnológica Federal do Paraná (UTFPR), Campus Pato Branco, PR, Brasil.

E-mail: janecler@utfpr.edu.br

(iD) https://orcid.org/0000-0002-7729-9501

\section{AGRADECIMENTOS}

Não se aplica.

\section{FINANCIAMENTO}

Não se aplica.

\section{CONSENTIMENTO DE USO DE IMAGEM}

Não se aplica.

\section{APROVAÇÃO DE COMITÊ DE ÉTICA EM PESQUISA \\ Não se aplica.}

\section{LICENÇA DE USO}

Autores mantêm os direitos autorais e concedem à revista ENSIN@ UFMS - ISSN 2525-7056 o direito de primeira publicação, com o trabalho simultaneamente licenciado sob a Licença Creative Commons Attribution (CC BY-NC-SA 4.0), que permite compartilhar e adaptar o trabalho, para fins não comerciais, reconhecendo a autoria do texto e publicação inicial neste periódico, desde que adotem a mesma licença, compartilhar igual.

\section{EDITORES}

Patricia Helena Mirandola Garcia, Eugenia Brunilda Opazo Uribe, Gerson dos Santos Farias. 


\section{HISTÓRICO}

Recebido em: 29/08/2021 - Aprovado em: 08/11/2021 - Publicado em: 15/12/2021.

\section{COMO CITAR}

MELLO, A. L; COLOMBO, J. A. A. Ensino de Função Afim através da Resolução de Problemas: Uma Intervenção no Ensino Médio. Revista ENSIN@ UFMS, Três Lagoas, v. 2, número especial, p. 67-89. 2021. 